\title{
DETAILING OF PLASTIC HINGES IN SEISMIC DESIGN OF CONCRETE STRUCTURES
}

\author{
Rajesh P Dhakal and Richard C Fenwick \\ Department of Civil and Natural Resources Engineering, University of Canterbury \\ Christchurch 8020, New Zealand
}

Biography: ACI member Rajesh P Dhakal is a Senior Lecturer in the Civil and Natural Resources Engineering Department at University of Canterbury. He received his BE from Tribhuvan University, ME from the Asian Institute of Technology (AIT) and $\mathrm{PhD}$ from the University of Tokyo. His research interests include performance based earthquake engineering, and analytical modeling and seismic design of structures.

ACI member Richard C Fenwick retired from the University of Auckland in 2002. During the last 5 years he has spent time working on the development of Structural Design Standards for Standards New Zealand and on research projects with staff and students at the Universities of Auckland and Canterbury in the field of structural concrete.

\begin{abstract}
In recent revisions of the Structural Design Codes in New Zealand, a number of changes have been made to seismic design provisions. One of the more significant revisions was the way in which the level of detailing is determined for potential plastic hinges. Previously the level of detailing was based principally on the structural ductility factor, which is broadly similar to the reduction factor, $\mathrm{R}$, used in US practice. With the revision it is based on the predicted magnitude of curvature that the plastic hinge is required to sustain in the ultimate limit state. This paper explains why the structural ductility factor does not give a reliable guide to the deformation sustained in an individual plastic hinge. In addition, based on test results of 37 beams, 25 columns and 36 walls, design curvature limits are proposed for different categories of plastic hinge.
\end{abstract}

Keywords: Material strain; Structural ductility; Plastic hinge, Curvature, Ductile, Nominally ductile, Limited ductile, Detailing.

\section{INTRODUCTION}

In New Zealand, capacity design is required in the design of all ductile structures. This involves identifying a ductile failure mechanism for the structure and locating the positions of the associated plastic hinges. These are referred to as primary plastic hinges and are likely to develop in regions of maximum moment due to the design actions, and these are the main source of inelastic response and ductile behavior of a structure. On the other hand, secondary plastic hinges are regions where inelastic actions (i.e. yielding) may develop due to mechanisms not considered in the analysis such as elongation of primary plastic hinges and changes in dynamic characteristics, which arise when primary plastic hinges are yielding. Secondary plastic hinges involve limited levels of inelastic deformation. Generally, the inelastic demand is considerably less in secondary plastic hinges than in primary plastic hinges. The regions outside the primary plastic hinges are designed with a specified margin of strength greater than the actions that can be applied to them when the primary plastic hinges are resisting their maximum strengths. This process is intended to ensure that in the event of a major earthquake the structure will be ductile, and that non ductile failure mechanisms will be suppressed.

In New Zealand, the new Loadings Code $^{1}$ (referred to as NZS 1170.5:2004 ${ }^{1}$ hereafter) requires the level of detailing used in potential plastic regions to be based on the predicted material strains imposed on the region in the ultimate limit-state. This is a significant change from the provision of detailing potential plastic hinges based on global displacement ductility demand, which existed in the previous version of New Zealand Loadings $\operatorname{Code}^{2}$ (i.e. NZS 4203:1992²). The 2006 revision of 
1 the New Zealand Concrete Code $^{3}$ (referred to as NZS 3101:2006 ${ }^{3}$ hereafter) is the first structural 2 code to be written to comply with the new seismic design approach recommended in NZS $3 \quad 1170.5: 2004^{1}$. For flexural members, NZS 3101:2006 ${ }^{3}$ specifies the material strain limits for 4 different levels of detailing in terms of nominal curvatures as actual material strains in 5 reinforcement and concrete cannot be easily determined. The curvatures are used as an index of the 6 expected strain levels in the plastic hinges in the ultimate limit state. the basis of the level of deformation they are required to sustain in the ultimate limit-state, considered this step as leading to more efficient structures with better defined levels of seismic performance. This is the first time that such a requirement has been introduced into a national seismic design code of practice. As shown in this paper, this step can be readily incorporated into current practice without involving appreciable extra effort in design. The reason behind the shift from the use of the global structural ductility factor to calculated curvature levels in plastic hinges is described in this paper.

In addition, the background to a proposed amendment of the current material strain (i.e. curvature) limits specified in NZS 3101:2006 ${ }^{3}$ is given. These proposed values, which as far as possible are based on test results, are simpler to apply than those in the first edition of NZS 3101:2006. The main objectives of seismic design provisions are that a structure can sustain a serviceability limit state earthquake with minimal damage, the design basis earthquake (return period of 500 years for most buildings) for the ultimate limit state with a high margin of safety against collapse and the maximum credible earthquake (return period of 2,500 years) with a margin of safety. The material strain limits given in this paper are intended to satisfy the serviceability criteria as well as both the design basis earthquake (i.e. ultimate limit state) and maximum credible earthquake criteria.

\section{RESEARCH SIGNIFICANCE}

This paper explains why global displacement ductility factor does not reliably represent the level of deformation demand in plastic hinges in reinforced concrete structures. It is proposed that nominal curvatures in potential plastic hinges, calculated by simplified rules, be used as an index to define the level of detailing required in the plastic hinges. Curvature limits for the different levels of detailing are proposed. As far as practical these are based on test results. This approach should allow the seismic performance to be better defined.

\section{STRUCTURAL DUCTILITY AND INELASTIC DEFORMATION IN PLASTIC HINGES}

The structural ductility factor, $\mu$, gives a measure of the ductility of a structure as a whole. However, as illustrated in Figure 1, the structural ductility factor does not give a reliable measure of the inelastic deformation imposed on any specific potential plastic hinge. Figure 1(a) shows a structural wall supported on a stiff foundation. The resultant load deflection relationship is shown on the right hand side of the figure. The ductility one displacement $(\mu=1.0)$ is relatively small as the deformation in the foundation and supporting structure is small. A similar structural arrangement is shown in Figure 1(b). In this case an identical wall to the one shown in Figure 1(a) is supported on a flexible foundation. When lateral seismic design forces are applied, the yielding displacement (i.e. $\mu=1.0$ ) is larger for this wall due to the flexible foundation. Note that the displacements used to calculate the displacement ductility in traditional sense are measured based on an absolute coordinate system, which includes the rigid body displacement due to the rotation of the foundation. As can be seen in the figure, a maximum allowable value of inelastic deformation of the plastic hinge, which is a true measure of required detailing, results in different values of maximum displacement ductility in these two systems. In other words, when the two structures are taken to the same level of ductility much greater inelastic deformation is imposed on the plastic hinge in the wall with the flexible foundation than in the case of the wall with the stiff foundation. It is this deformation which is the main factor determining the level of detailing required to prevent failure. From this, it can be seen that the structural ductility factor does not give a reliable guide to the inelastic deformation demand placed on plastic hinges. It was on this basis that NZS 1170.5:2004 
and NZS 3101:2006 ${ }^{3}$ require the inelastic deformation demand consistent with the ultimate limit state actions to be used to determine the level of detailing.

A general term "material strain" is introduced in NZS 1170.5:2004 ${ }^{1}$ to cover different forms of inelastic deformation (i.e. curvature, shear deformation, axial strain etc.) in a plastic hinge. In NZS $3101: 2006^{3}$, three levels of detailing are introduced to cover different material strain demands, namely nominally ductile, limited ductile and ductile. The nominally ductile plastic region (NDPR) requires no special detailing for seismic actions. Members designed with nominally ductile plastic regions have limited ductility, which is sufficient to enable the levels of moment redistribution defined in the Standard to be sustained. However, the level of ductility is generally inadequate for plastic regions that are required to sustain appreciable inelastic deformation in a major earthquake. Typically, NDPR detailing will be found in regular nominally ductile structures (formerly referred to as elastically responding structures). Limited ductile plastic region (LDPR) detailing is required in plastic regions that are predicted to sustain moderate levels of inelastic deformation in the ultimate limit state, while ductile plastic region (DPR) detailing is required where high inelastic deformation demands are predicted to occur in the ultimate limit state.

\section{ESTIMATION OF MATERIAL STRAIN (CURVATURE) DEMAND Calculation of inter-story drift and plastic hinge rotations in the ultimate limit state} The magnitude of the predicted inelastic rotation acting in primary plastic regions may be obtained by a number of different methods. With time history analyses, in which inelastic deformation characteristics of members are modelled and P-delta actions are included, the plastic hinge rotations may be obtained directly from the output of the analysis. Questions remain on which ground motion records should be used in nonlinear time-history analysis. Different ground motions, even when they are scaled to match the design spectra, can result in very different values of inelastic deformation ${ }^{4}$. Consequently, to know the reliability of the adopted value of plastic hinge rotation, a large number of analyses using different earthquake records are required. Elastic time-history analyses are not permitted by NZS1 170.5:2004 ${ }^{1}$. Where other elastic based analyses are used, such as the equivalent static or the modal response spectrum methods, the ultimate limit-state lateral displacement envelope is obtained by modifying the corresponding elastically predicted envelope, first to allow for P-delta actions and second for inelastic deformation, as specified in NZS 1170.5:2004.

The ultimate inter-storey drift in any storey in a frame or in a wall structure may be broken down into elastic and plastic components, as illustrated in Figure 2. The elastic component may be taken as equal to the value found from an equivalent static or first mode analysis of the structure. Note that this gives a conservative estimate of elastic limit for storeys other than where the first yielding occurs in a structure as different storeys reach inelastic stage at different stage. Alternatively, a less conservative value of the elastic component is found by scaling the elastic value predicted from the analysis by the ratio of average design flexural strength of the primary plastic regions in the storey under consideration to the corresponding average value of the seismic design moments. The plastic inter-storey drift is obtained by subtracting the elastic component of inter-storey drift from the total inter-storey drift. The resulting plastic rotations in the plastic hinges may be calculated as illustrated in Figure 2 from the geometry. As shown in Figure 2(a), the column rotation in a storey $\theta_{c}$ is given by:

$$
\theta_{c, i}=\frac{\delta_{i, p}}{h_{i}} \quad \theta_{c, i-1}=\frac{\delta_{i-1, p}}{h_{i-1}}
$$

where $\delta_{i, p}$ is the inter-storey displacement due to plastic drift in the storey $i$ and $h_{i}$ is the height of storey $i$. In a frame, the plastic rotation of a beam in any level may be estimated based on the average gradient associated with the plastic deformation in the storey above and the storey below the level of the beam being considered. Hence, the corresponding plastic rotation in a plastic hinge, $\theta_{p}$, is given by: 


$$
\theta_{p}=\frac{\theta_{c, i}+\theta_{c, i-1}}{2} \times \frac{L}{L^{\prime}}
$$

where $L$ is the span of the beam between column centre-lines and $L^{\prime}$ is the distance between the centres of the plastic hinges in the beam, which can be calculated if the location and length of the plastic hinge is known. The position of plastic hinge can be determined from the bending moment profile and the plastic hinge lengths for different types of members are specified in the design codes. Similarly, the rotation in columns or walls can be found from the geometry and inter-storey drift of the storey containing the wall or column. As illustrated in Figure 2(b) a designer may, in some situations, permit plastic hinges to form in some columns provided other columns or walls in the structure have a margin of strength significantly above that required to prevent the formation of a column sway mechanism in a major earthquake. The expression for the plastic rotation in walls and columns can be readily derived from the geometry shown in Figures 2(b) and (c).

\section{Calculation of curvature}

It is important to recognise the different forms of plastic regions (namely unidirectional and reversing) that may develop. In reversing plastic regions, inelastic rotations or shear deformations in both directions (positive and negative) are induced in the same zone as the structure sways backwards and forwards. However, in unidirectional plastic regions the inelastic curvature accumulates in the same direction ${ }^{5-6}$. The predicted maximum curvature demand, or material strain, in a plastic region is obtained by dividing the plastic hinge rotation, $\theta_{p}$, by the effective plastic hinge length, $l_{\text {eff, }}$ and adding on the curvature, $\phi_{y}$, associated with the first significant yield in the plastic region. Hence, the maximum curvature in a plastic hinge is given by:

$$
\phi_{u}=\frac{\theta_{p}}{l_{e f f}}+\phi_{y}
$$

Figure 3 shows effective plastic hinge lengths for reversing and unidirectional plastic hinges in beams. It should be noted that the term "effective plastic hinge length", which is used to calculate the material strain, is a length over which the plastic curvature is assumed to be uniform. This is much shorter than (and should not be mistaken with) the "ductile detailing length" that defines the distance over which yielding of the reinforcement, or spalling of the concrete, may be expected to occur. Any detailing that is required to sustain large plastic deformation to avoid premature failure should extend over the full ductile detailing length, which is specified through the detailing instructions in a concrete structures standard (for beams, it is taken as 2 times the overall depth). For a reversing plastic hinge, or a unidirectional plastic hinge close to the supporting member, where yielding can only occur on one side of the critical section, the effective plastic hinge length in beams or columns is taken as the lesser of either of $h / 2$ or the larger of $h / 4$ or $0.2 M / V$ (moment divided by shear at the critical section), where $h$ is the section depth. For walls the effective plastic hinge length is taken as the smaller of $L_{w} / 2$ or $0.15 M / V$, where $L_{w}$ is the length of the wall. As shown in Figure 3(b), for unidirectional plastic hinges, which form away from the supporting member, yielding can develop on both sides of the critical section. In such cases, the effective length of the plastic hinge may be taken conservatively as twice the corresponding value for reversing plastic hinges. In these cases the gradient of the moment diagram (equal to the shear force) is low and hence a little strain hardening can cause the plastic length to extend over an appreciable distance. In practice where unidirectional plastic hinges form, the curvature of the plastic hinge located against the face of the supporting member (generally a column) limits the deformation that the member can sustain.

In design, the curvature limits in plastic hinge regions are required to ensure that the material strains do not exceed values appropriate for the level of detailing that is used. Consequently, a number of conservative approximations may be made with more detailed calculations required only if the simplified methods indicate curvature demand is too high. Conservative short cuts, which may be made for determining required detailing levels in moment resisting frame structures include: (i) checking curvatures only for beams in the storey sustaining the greatest inter-storey drift and using 
the level of detailing required for this beam for a wide group of beams; (ii) assuming the rotation of a column due to plastic deformation, $\theta_{\mathcal{C}}$ is equal to the drift in the storey with the maximum interstorey drift; and (iii) assuming the drift due to the elastic deformation of the frame is negligible.

\section{CURRENT PROVISIONS RELATED TO MATERIAL STRAIN LIMITS}

The approach followed in NZS3101:2006 ${ }^{3}$ for calculating curvatures is similar to that proposed by Baker in $1956^{7}$. Uniform plastic strains are assumed to develop in a beam, column or wall for an effective plastic hinge length. In actual flexural members, the strains are far from uniform. However, by selecting an appropriate "effective plastic hinge length", $l_{\text {eff }}$, it is considered that a uniform curvature could be used throughout $l_{\text {eff }}$ to predict the total plastic rotation. These assumptions are illustrated in Figure 4.

Current recommendations for material strain limits in NZS 3101:2006 ${ }^{3}$ are taken as a product of the coefficient listed in Table 1 and the curvature corresponding to first yield of the reinforcement, which can be calculated using the neutral axis depth determined by section analysis. These limits are based on experience/intuition and were intended to be conservative. Although there was limited time available during the revision of the Code to define limiting material strains based on experimental data, the committee was not prepared to wait until the next revision of the code to adopt this new philosophy. It was felt that the progress made by merely embarking on this more convincing approach to the detailing of plastic regions would outweigh the impediment due to lack of quantitatively verifiable inelastic demand limits. Subsequently, conservative limits were adopted on an ad hoc basis and the research communities in New Zealand were requested to come up with more robust values of the material strain limits. The changes in the material strain limits suggested in this paper will both simplify the design process and give material strain limits which are more soundly based than is currently the case.

\section{INADEQUACY OF ANALYSIS IN PREDICTING MATERIAL STRAIN LIMITS}

The actual strain levels in the longitudinal reinforcement and concrete in a plastic hinge cannot be accurately predicted. Figure 5 illustrates the actions in a beam plastic hinge located close to a column. Part (a) of the figure indicates a typical crack pattern, while part (b) shows the profile of flexural tension force in reinforcing bars. As shown in Figure 5(b) the longitudinal beam reinforcement yields over a length of " $g+e+f$ ". The distance " $e$ " in the beam is a function of the difference between the maximum bending moment resisted at the critical section of the plastic region, $M_{\max }$, and the moment which induces first yield of the longitudinal reinforcement, $M_{y 1}$. The value of the length " $e$ " is given by:

$$
e=\left[\frac{M_{\max }-M_{y 1}}{M_{\max }}\right] \frac{M}{V}
$$

where $M / V$ is the ratio of moment to shear at the critical section. The increase in $M_{\max }$ above the moment at first yield depends mainly on the strain hardening characteristics of the reinforcement. The additional extension of yielding in the beam, which is known as the tension lag and denoted as $f$ in Figure 5(b), is associated with diagonal tension cracking in the beam, as illustrated on the free body shown on the right hand side of Figure 5(a). In the free body diagram, it can be seen that the compression force in Section 2 is in equilibrium with the tension force in Section 1. Hence, if the stirrups do not carry any shear, the product of $T_{1}$ and the internal lever arm $(j d)$ gives the moment $M_{2}$ at Section 2, not $M_{1}$ at Section 1. Therefore, yielding has to extend for a distance $x_{d}$ (projection of the diagonal crack) to be in equilibrium with the compression force at the section at the head of the crack. On the other hand, when the stirrups resist the full shear $V_{s}$, the resultant of the vertical stirrup forces will be at half-way along the diagonal crack. In this case, the product of $T_{1}$ and $j d$ corresponds $M_{2}-V_{s} x_{d} / 2$, which is the moment at the section mid-way between 1 and 2 . Hence, the yielding extension in this case is $x_{d} / 2$. Generally, at the end of the plastic region, provided the shear stress is sufficient to cause diagonal cracking, the value of $x_{d}$ is approximately equal to the effective depth. With reversed inelastic cyclic loading diagonal tension cracks form from both faces of the beam. The intersection of these cracks effectively destroys the shear that can be resisted by the 
concrete alone; i.e. $V_{c}$ is zero. In this situation, the value of tension lag, $f$, for practical purposes can be taken as half the effective depth, $d / 2$.

The formation of diagonal cracks in the beam column joint causes yielding to extend for some distance through the joint zone. The extent of yield penetration into or through a joint, shown as " $g$ " in Figure 5(b), depends on many factors, the most important of which are the number and magnitude of inelastic load cycles, the depth of the column relative to the diameter of bar, the reinforcement yield stress, the axial load on the column and the stress in the column reinforcement. This yield penetration length increases as bond resistance is lost due to yielding of the reinforcement and cyclic loading. Figure 5(c) shows the curvature distribution along a plastic region in a beam based on the strains in the flexural tension reinforcement. For comparison the assumed analytical curvature over the length $l_{\text {eff }}$ is also shown. The yield penetration and anchorage pull out of the reinforcement in the joint zone results in cracks forming either at or close to the face of the column or/and at the face of the extreme reinforcement in the column. It may be noted that the yield extension of the reinforcement over the distance " $g+e+f$ ", which is equal to the distance between $\mathrm{C}$ and $\mathrm{A}$ in Figure 5(a), is associated with flexural compression of the concrete between the face of the column and point B. Hence, the assumption of plane sections remaining plane is at best, even for unidirectional plastic regions, a very rough approximation. It should also be noted that the assumption that the inelastic curvature accounts for the total inelastic displacement is not strictly correct, as shear deformation does not induce curvature and it has been found to account for 30 percent or more of the total displacement in beams subjected to extensive inelastic cyclic loading ${ }^{8-10}$. For these two reasons, namely plane sections not remaining plane and shear deformation being ignored in the calculation of curvature limits, analytical curvatures in unidirectional plastic hinges cannot be used to predict realistic strain levels in either the reinforcement or concrete.

With inelastic cyclic loading, an additional complication arises due to elongation of plastic hinges ${ }^{10}$. With flexural cracking in beams, columns and walls elongation occurs unless they are subjected to moderate to high axial load ratios. This elongation increases substantially when inelastic deformation is applied. In unidirectional plastic hinges, elongation occurs as the tensile strains in the reinforcement are greater than the corresponding compression strains in the concrete. With reversing plastic hinges, there are two causes of elongation.

1. When longitudinal reinforcement yields, wide cracks develop. Micro cracks form round the bars and the slip of the bars through the concrete results in chips and aggregate particles being pulled into the cracks. Additional material is dislodged from the crack surfaces due to shear displacements, which develop across cracks. This material tends to prevent the cracks from closing when the direction of moment and shear reverse. Consequently, the concrete dilates when subjected to inelastic cyclic loading ${ }^{10}$.

2. Diagonal compression forces are sustained in the beam web due to the action of the shear reinforcement. The longitudinal component of these forces causes the flexural tension force at a section to be greater than the corresponding flexural compression force. Hence, a bar previously yielded in tension is not subjected to sufficient compression to cause it to yield back and close the crack upon load reversal. This causes a part of the strain to be left unrecovered, thereby leading to a permanent elongation ${ }^{10}$.

Hence, the aforementioned issues must be addressed before realistic strain levels can be predicted in reinforcement or concrete.

\section{ASSESSMENT OF LIMITING MATERIAL STRAINS FROM TEST RESULTS}

To avoid the analytical problems described above, the proposed material strain limits for ductile and limiting ductile members are derived from test results of structural members. For each type of member an effective plastic hinge length is assumed. Using this value, an ultimate curvature is calculated from the test results. This value is based on the assumption that all the inelastic deformation arises from curvature in the effective plastic hinge length. The limiting rotation is calculated from the displacement sustained when the strength of the member degrades to 80 percent 
of its theoretical strength. The process of assessing a limiting curvature from individual test results for a member is illustrated in Figure 6 and set out in the steps given below.

1. Each test unit is assessed to determine if the detailing in the potential plastic region satisfied the requirements for nominally ductile, limited ductile or ductile detailing, as set out in NZS 3101:2006 ${ }^{3}$, or if it did not qualify for any of these.

2. From the pre-yield loading cycles, the displacement sustained at approximately $3 / 4$ of the theoretical strength is extrapolated linearly to the load level corresponding to the theoretical strength of the member. This is taken as the ductility one displacement, $\delta_{e}$, as illustrated in Figure 6.

3. Scrutinising a large number of test results showed that in the majority of cases failure occurred in a load cycle which involved displacements ranging from a large negative displacement to a large positive displacement, or vice versa. This indicates that it was the range of total displacement from the start to end of a half cycle that was responsible for failure, rather than the peak displacement measured from the initial position at the start of the test. In recognition of this, the ultimate curvature is based on the average of the peak displacements sustained in the half cycle before failure occurred. With reference to Figure 6, this displacement is equal to $0.5 \mid\left(\delta_{\max }^{+}-\delta_{\max }\right)$, where $\delta_{\text {max }}^{+}$and $\delta_{\text {max }}^{-}$are the maximum positive and negative displacements sustained in the half cycle before the load dropped below $80 \%$ of the theoretical strength. As all tests considered in this paper are on reversing plastic hinges, averaging the peak displacements in the two directions is justified. Nevertheless, this approach underestimates the displacement capacity of unidirectional plastic hinges, for whish the absolute maximum displacement may be a more reasonable measure of the displacement capacity.

4. In many tests, several cycles of loading were applied between specific positive and negative displacements before failure occurred. Clearly in such cases, the member would have been capable of sustaining one or more number of larger displacement cycles before failure occurred if the previous load cycles had not been applied. Results of several beam tests suggested that this effect could be conservatively predicted by multiplying the critical displacement found in step 3 by $1.05^{(n-1)}$ but not greater than 1.5 , where $n$ is the number of times the positive and negative displacement peaks are sustained in the displacement cycles being considered before the applied force resisted at a peak displacement drops below 80 percent of the theoretical strength. This process is illustrated in Figure 6, where in the half load cycle between $\delta^{+}{ }_{\max }$ and $\delta_{\max }$ the value of $n$ was 4 before the load sustained at the peak positive and negative displacements dropped to $80 \%$ of the theoretical strength $\left(0.8 H_{i}\right)$. Consequently, the critical displacement found in step 3 in this case would be multiplied by $1.05^{3}$.

The ultimate curvature due to plastic deformation obtained from a test, $\phi_{p}$, calculated as set out in steps 1 to 4 is given by:

$$
\phi_{p}=\frac{\left(0.5 \alpha_{r}\left(\delta_{\max }^{+}-\delta_{\max }^{-}\right)-\delta_{e}\right)}{\left(\frac{M}{V}-\frac{l_{e f f}}{2}\right) l_{e f f}}
$$

where $l_{\text {eff }}$ is the effective plastic hinge length, $\alpha_{r}$ is the repetition coefficient calculated as the lesser of $1.05^{(n-1)}$ and 1.5 , and $\delta^{+}{ }_{\max }, \delta_{\max }^{-}, \delta_{e}$ and $n$ are as defined in steps 1 to 4 above.

\section{PROPOSED MATERIAL STRAIN LIMITS IN POTENTIAL PLASTIC REGIONS}

A major factor influencing the behaviour of plastic hinge zones is the type of deformation that they are required to sustain. As outlined in references ${ }^{5-6}$, plastic hinges may be subjected to reversing or unidirectional inelastic actions. The vast majority of tests on plastic regions, which may be classified as ductile or limited ductile, have been made on reversing actions. The few beams, which have been tested as unidirectional plastic hinges in ductile plastic regions, have indicated that these zones can sustain in excess of twice the rotation in a comparable reversing plastic hinge ${ }^{10}$. For nominally ductile plastic regions, the situation is different and no suitable test results could be found in the readily available literature for the beams subjected to cyclic inelastic loading. 


\section{Ductile and limited ductile plastic regions}

From an analysis of test results, Priestley and Kowalsky ${ }^{11}$ proposed that the curvature in a plastic region in a member sustaining a section ductility of one, $\phi_{y}$, could be taken as a product of a constant and the yield strain divided by the overall depth of the member. The constant was found to vary for different types of members and reinforcement arrangements, but it was generally close to 2.0, and for simplicity it has been assumed to be equal to 2.0 for all cases. It is decided to give limiting curvature values in ductile and limited ductile regions as a multiple of $\phi_{y}$, as this avoids the need for detailed analysis of the section to find the curvature at first yield. On this basis, the curvature $\phi_{y}$ in a potential plastic region, corresponding to the stage where significant inelastic deformation is initiated, is taken as:

$$
\phi_{y}=\frac{2 \varepsilon_{y}}{h}
$$

where $\varepsilon_{y}$ is the yield strain and $h$ is the member depth or wall length.

The maximum curvature for the ultimate limit state is taken as a product of $\phi_{y}$ and two factors, namely $K_{d}$, which allows for the type of member and level of detailing used in the plastic region, and $K_{y}$, which allows for the reinforcement grade. While $\phi_{y}$ increases with the yield stress of reinforcement, the ultimate curvature that can be sustained in many cases depends on the strain capacity of the concrete and the buckling resistance of the reinforcement. The grade of reinforcement does not have a major influence on the concrete strain capacity. Nevertheless, the buckling tendency of the main bars and consequently the anti-buckling resistance of the provided reinforcement depend, to some extent, on the yield strength of the longitudinal reinforcement ${ }^{12-13}$. Analysis of experimental results from beam, column and wall tests indicates that for yield stress levels above $425 \mathrm{MPa}(62 \mathrm{ksi})$ there was no significant change in the ultimate curvature that could be sustained. The introduction of the $K_{y}$ factor allows for this observation and it effectively limits the ultimate plastic curvature that can be used with reinforcement that has a yield stress in excess of $425 \mathrm{MPa}(62 \mathrm{ksi})$ to the value that would be sustained with a yield stress of $425 \mathrm{MPa}(62 \mathrm{ksi})$. With this adjustment the limiting ultimate limit-state curvature in a ductile or limited ductile plastic hinge is given by:

$$
\phi_{\max }=K_{d} K_{y} \phi_{y}
$$

where $K_{d}$ is as defined above, $\phi_{\mathrm{y}}$ is given by Equation 6 and $K_{y}$ is the factor allowing for reinforcement grade, which is given by:

$$
K_{y}=1.0 \text { for } f_{y} \leq 425 \mathrm{MPa} \quad(62 \mathrm{ksi})
$$

$$
=425 / f_{y} \text { for } f_{y} \geq 425 \mathrm{MPa} \quad\left(=62 / f_{y} \text { for } f_{y} \geq 62 \mathrm{ksi}\right)
$$

\section{Beams}

Limiting curvatures were calculated from 37 beam tests taken from the literature ${ }^{8-9,14-16}$. There were no test units that could be classified as either limited ductile or nominally ductile beams. Of these, 19 were classified as containing ductile detailing and 18 tests were discarded as they contained details not representative of current practice. In particular, many of these test units had shear reinforcement that was in excess of twice, and in some cases up to 7 times, the amount required by current practice. Most of these discarded beams sustained very high curvatures and they did not exhibit the shear pinching characteristic more representative of current practice. Some beams ${ }^{8-9}$ differed from the others in that yield penetration of the reinforcement into the supporting column was limited by welding additional bars onto the beam reinforcement in the anchorage zone in the supporting member. This reduced the pullout of the reinforcement and hence led to conservative values of curvature in the plastic regions. The results of the tests for beams with ductile plastic detailing are summarised in Table 2 and shown in Figure 7, where the ultimate curvatures are plotted against the shear stress (maximum shear force divided by the shear area) normalised with respect to the square root of the concrete compressive strength. The shear stress 
level, within the range of tests that were examined, appeared to have little influence on the ultimate curvature.

\section{Columns}

Limiting curvatures were calculated from 25 column tests ${ }^{17-20}$. Of these, 9 were classified as having ductile plastic regions and 7 as limited ductile plastic regions. The remaining 9 test units did not satisfy the requirements for either ductile or limited ductile detailing. The results of the analyses are summarised in Table 2 and Figure 8, where the ultimate curvatures are plotted against the axial load ratio $\left(N / A_{g} f_{c}\right)$. In this case, the maximum axial load ratio $\left(N / A_{g} f_{c}\right.$ ') of the test units for ductile plastic region considered was equal to 0.3. It is apparent in the figure that increasing axial load, $N$, does not significantly reduce the ductility of the limited ductile plastic regions, which is one of the objectives on which the confinement criteria are based ${ }^{3}$. The same condition is assumed to apply to columns with ductile plastic regions. As in the beams, the ultimate curvatures in column plastic hinges were also found to be independent of shear stress.

\section{Walls}

Two different sets of wall tests were examined, namely thin singly reinforced walls and ductile walls with two layers of reinforcement (one for each side face of the wall). Ultimate curvature values were determined from the experimental results of 29 thin singly reinforced walls ${ }^{21-25}$. Of these nine were rejected, five on the basis they were not representative of practice and 4 as they had aspect ratios (i.e. length/height) less than 0.75 and failed by sliding shear. At present, there is no codified method in NZS 3101:2006 ${ }^{3}$ for assessing sliding shear in walls. The results from units with height to thickness ratios, which exceeded the permissible slenderness ratio by more than 35 percent, were also excluded from the data as were the results of two tests where the ultimate curvatures were more than 50 percent greater than those of similar companion units. The results obtained from remaining units are listed in Table 2 and shown in Figure 9, where the ultimate curvatures are plotted against the factor $\left(\rho f_{y} / f_{c}{ }^{\prime}+N / A_{g} f_{c}{ }^{\prime}\right)$, which gives an assessment of the maximum compression force induced in the wall.

The test walls described in references ${ }^{22-24}$ were constructed with vertically concave shape with the initial vertical alignment imperfection equal to the maximum permissible for standard construction. The other feature to note is that three of the walls tested by McMenamin ${ }^{24}$ failed, or partially failed, when some of the vertical reinforcement fractured. The results obtained from these walls gave limiting curvatures that were amongst the lowest observed in the series of tests. The reason for the apparent lack of ductility of this reinforcement is unknown. The reinforcement did not have a distinct yield point, but the nominal yield stress measured at an offset strain of 0.2 percent was $504 \mathrm{MPa}$ (73ksi) and the ultimate stress was 1.28 times the yield stress at a strain of 20 percent. The results of these three units have also been included in Table 2 and in Figure 9.

The results of tests ${ }^{26-28}$ on 7 ductile rectangular walls reinforced with two layers of reinforcement were also analysed. Several of these walls formed wall elements in coupled walls. The axial load on these varied significantly during the test. Due to the widely varying axial load levels and the limited number of tests, the ultimate curvatures have not been shown in a figure. However, the average ultimate curvature, the standard deviation and the calculated lower characteristic curvature calculated from these tests are included in Table 2.

\section{Nominally ductile plastic regions}

None of the 98 tests reviewed in this paper covered the details that could be categorised as nominally ductile plastic regions. To fill the gap in our knowledge of the behaviour of nominally ductile plastic regions, a research project has been started at the University of Canterbury. However, it will be some time before these results are available. Hence, curvature limits for this category are proposed based on engineering judgement. For members where the design strength is limited by flexure rather than shear, the limiting curvatures in nominally ductile unidirectional plastic regions of beams are taken as the smaller of the values corresponding to: a compression strain in the concrete of 0.004 , which is generally taken as a strain when spalling of the concrete may be expected; and a tensile strain in the reinforcement of 0.016 . 
For reversing plastic regions, it is proposed that the corresponding limits are taken as approximately 60 percent of the corresponding unidirectional limits, which, with a little rounding give a limiting concrete compressive strain of 0.0025 and a limiting tensile reinforcement strain of 0.010 . For nominally ductile plastic regions, where the design shear strength controls the design strength of the member, no inelastic deformation capacity should be assumed.

\section{Recommendations for material strain limits}

As mentioned earlier, the material strain limit for diagonally reinforced coupling beams is given in NZS $3101: 2006^{3}$ as a shear deformation as these members deform with little or no flexural deformation. This value was derived from an assessment of limited experimental work on coupling beams ${ }^{28-29}$. Suggesting a change in the current limit for shear deformation is not in the scope of this paper. Furthermore, no material strain limits have been proposed for axial tension or compression at present.

Table 3 gives the recommended values for the coefficient $K_{d}$ used in Equation 7 for calculating curvature limits for reversing plastic hinge regions in beams, columns and walls. These are based on suitably rounded curvature limits corresponding to lower characteristic values summarised in Table 2. However, as there were no suitable tests for limited ductile plastic regions in beams the curvature limit has been placed approximately mid way between those for nominally ductile and ductile plastic regions. The recommended limiting curvatures for nominally ductile beams and walls are similar to the current values in NZS3101:2006 ${ }^{3}$, though the maximum tensile strain limits have been changed. With the proposed values the curvature limit is approximately $2.5 \phi_{y}$ to $4.0 \phi_{y}$ for reinforcement grades 500 and 300 respectively, where $\phi_{y}$ is given by Equation 6 . For unidirectional plastic regions, the curvature limits may be doubled for ductile and limited ductile beams and columns and for nominally ductile plastic regions the strain limits may be increased to 0.004 and 0.016 for concrete and reinforcement, respectively.

\section{DISCUSSION}

The limiting material strains listed in the paper are for the ultimate limit state (design basis earthquake) where a high margin of safety is required. However, it is believed that plastic regions proportioned to meet these limits will also satisfy the greater deformation required for the maximum credible earthquake (return period of 2,500 years) to be met with an adequate margin of safety. There are two reasons for this.

- The maximum deformation limit from each test was based on displacement cycles with positive and negative peaks of nearly equal value. However, in an earthquake the peak displacement is only sustained in one direction.

- A decrease in the flexural resistance of a plastic region in practice results in a redistribution of forces to other plastic regions in indeterminate structures. Hence, the average strength and deformation capacities of plastic hinges in a region of the structure (such as plastic hinges in one storey of a moment resisting frame building) is the controlling factor rather than the ultimate design limits based on the lower characteristic values. The difference between the mean and lower characteristic values of deformation capacity is appreciable, as can be seen from Table 2. Allowance for this effect can make an appreciable difference to the total displacement that can be sustained before collapse occurs.

It should be noted that the proposed curvature limit was found from displacements measured in tests on the basis of the assumption that the inelastic curvature accounted for the inelastic displacement. This is not strictly correct, as shear deformation does not induce any curvature and it has been found to account for 30 percent or more of the total displacement in beams subjected to extensive inelastic cyclic loading ${ }^{8-10}$. Nevertheless, shear displacements in plastic regions in columns and walls are generally considerably smaller than the corresponding values in beams. It should also be noted that the displacement history imposed by an earthquake is likely to have a significant influence on the maximum deformation that can be sustained before failure. If the maximum deformation is imposed near the start of a ground motion when the plastic regions have little damage, they are 
likely to be able to sustain greater deformation without failure than if the maximum deformation was imposed near the end of the ground motion. Analysis of test results on beams has shown that the dissipated energy is not in itself a good guide to deformation capacity. It was found that greater energy could be dissipated when a large number of relatively small displacement cycles are applied than when a relatively few large displacement cycles are applied ${ }^{30}$.

Although the proposed curvature limits for beams and columns may appear at first glance to be more conservative than the values given in NZS 3101:2006 ${ }^{3}$, they are not necessarily so due to the way they are calculated. In the proposal, the limiting curvatures are given in terms of a multiple of a curvature corresponding to the initiation of significant inelastic deformation. This curvature limit is significantly larger than the first yield curvature on which the curvature limits are currently based in NZS 3101:2006 ${ }^{3}$. Moreover, the use of a simple equation to estimate the curvature initiating significant inelastic behaviour for ductile and limited ductile plastic regions simplifies design calculations compared with the requirements given in NZS 3101:2006 ${ }^{3}$.

The material strains (curvatures) calculated by the design approach outlined in this paper should be considered as an index to the conditions in a plastic hinge; they are not true curvatures. In particular, reinforcement strains assessed from these curvatures can be considerably greater than the actual values. In practice, provided that seismic grade reinforcement (with a strain at maximum stress equal to or greater than 10\%) is used, the plastic rotations should not be limited by the reinforcement. Moreover, a relatively simple failure criterion has been adopted in assessing the ultimate deformation capacity of members and only a limited number of test results which were readily available were assessed in this paper. There is scope for further research looking at a wider range of test results and in assessing material strain limits by more sophisticated techniques based on damage indices.

\section{CONCLUSIONS}

The following conclusions can be drawn based on the discussions and results presented in this paper:

1. To improve the reliability of seismic performance of structures, NZS 1170.5:2004 ${ }^{1}$ introduced the requirement that the detailing of plastic regions be determined on the basis of calculated material strains they sustain when subjected to the deformations defined in the ultimate limit state. Subsequently, NZS 3101:2006 ${ }^{3}$ has set material strain limits for three different types of plastic regions. This is a paradigm shift from the previous approach of designing and detailing all plastic regions based on global structural displacement ductility factor. It has been shown in this paper that the structural ductility gives a poor indication of the required level of deformation in plastic regions.

2. Two types of plastic hinges (namely unidirectional and reversing) based on the nature of inelastic action and three types of plastic regions (namely ductile, limited ductile and nominally ductile) based on the expected level of inelastic deformation have been explained. The basis of calculating a plastic hinge rotation and hence material strain (curvatures in plastic hinges) has been outlined together with a number of approximations which may be used to simplify the design procedure.

3. Issues related to: (i) the very assumption of plane section remains plane being invalid; (ii) the predicted deformation not relating to curvature unless shear deformation is excluded; and (iii) inability of analytical models to take into account elongation of plastic hinges that occurs invariably during reversed cyclic actions; render it difficult for material strain (curvature) limits to be predicted analytically. Hence, experimental data have been used to establish curvature limits in this paper.

4. Based on the analysis of test results from 37 beams, 25 columns and 36 walls, recommendations have been made for material strain limits for limited ductile and ductile plastic regions. The proposed material strain limits are intended to provide a high margin of safety against failure in the ultimate limit state earthquake and an adequate margin of safety against collapse for the maximum credible earthquake with a return period of 2,500 years. 
These new material strain limits have been proposed as an amendment to the current values of 2 NZS 3101:2006 3 .

\section{REFERENCES}

1. SANZ, "Structural Design Actions, Part 5: Earthquake Actions, New Zealand", NZS 1170.5:2004, Standards Association Wellington, NZ, 2004.

2. SANZ, "General Structural Design and Design Loadings for Buildings Standard", NZS 4203:1992, Standards Association Wellington, NZ, 1992.

3. SANZ, "Concrete Structures Standard”, NZS3101:2006, Standards Association Wellington, NZ, 2006.

4. Dhakal, R. P., Mander, J. B. and Mashiko, N., "Identification of critical ground motions for seismic performance assessment of structures", Earthquake Engineering and Structural Dynamics, Vol. 35, Issue 8, June 2006, pp. 989-1008.

5. Fenwick, R. C., Dely, R. and Davidson, B. J., "Ductility demand for uni-directional and reversing plastic hinges in ductile moment resisting frames", Bulletin of NZ Society for Earthquake Engineering, Vol. 32, No. 1, Mar. 1999, pp. 1-12.

6. Megget, L. M. and Fenwick, R. C., "Seismic behaviour of a reinforced concrete portal frame sustaining gravity goads", Bulletin of NZ Society for Earthquake Engineering, Vol. 22, No. 1, Mar. 1989, pp. 39-49.

7. Baker A. L. L., "Ultimate Load Theory Applied to the Design of Reinforced and Prestressed Concrete Frames", Concrete Publications Limited, London, 1956.

8. Fenwick, R. C., and Fong, A., "The behaviour of reinforced concrete beams under cyclic loading", Bulletin NZ Society for Earthquake Engineering, Vol. 12, No. 2, June 1979, pp. 158-167.

9. Fenwick, R. C., Tankat, A. T. and Thom, C. W., "The deformation of reinforced concrete beams subjected to inelastic cyclic loading- Experimental results", University of Auckland, School of Engineering Report No. 268, Oct. 1981, 72 pages.

10. Fenwick, R. C. and Megget, L. M., "Elongation and load deflection characteristics of reinforced concrete members containing plastic hinges", Bulletin of NZ Society for Earthquake Engineering, No. 1, Vol. 26, Mar. 1993, pp. 28-41.

11. Priestley, N. J. M. and Kowalsky, M. J., "Direct displacement based design of concrete buildings", Bulletin of New Zealand Society for Earthquake Engineering, Vol. 33, No. 4, Dec. 2000, pp. 421-444.

12. Dhakal, R. P. and Maekawa, K., "Path-dependent cyclic stress-strain relationship of reinforcing bar including buckling". Engineering Structures, Vol. 24, No. 11, Nov. 2002, pp. 1383-1396.

13. Dhakal, R. P. and Maekawa, K., "Reinforcement stability and fracture of cover concrete in RC members". Journal of Structural Engineering, Vol. 128, No. 10, Oct. 2002, pp. 1253-1262.

14. Brown, R. H. and Jirsa, J. O., "Reinforced concrete beams under reversed loading", Journal of American Concrete Institute, Vol. 68, No. 5, May 1971, pp. 380-390.

15. Scribner, C. P. and Wight, J. K., "Delaying shear strength decay in reinforced concrete flexural members under large load reversals", Dept. of Civil Engineering, University of Michigan, Report No. UMEE 78R2, May 1978.

16. Popov, E. P. Bertero, V. V. and Krawinkler, H., "Cyclic behaviour of three concrete flexural members with high shear", Earthquake Engineering Research Center, University of California, Berkeley, Report no. EERC 72-5, Oct. 1972. 
17. Ang, B. G., "Ductility of reinforced concrete bridge piers under seismic loading", Dept. of Civil Engineering, University of Canterbury, Report No. 81-3, Feb. 1981.

18. Soesianawati, M. T., "Limited ductility design of reinforced concrete columns", Dept. of Civil Engineering, University of Canterbury, Report No. 86-10, Mar. 1986.

19. Gill, W. D., "Ductility of rectangular reinforced concrete columns with axial load", Dept. of Civil Engineering, University of Canterbury, Report No. 79-1, Feb. 1971.

20. Tanaka, H., "Effect of lateral confining reinforcement on the ductile behaviour of reinforced concrete columns", Dept. of Civil Engineering, University of Canterbury, Report No. 90-2, Jun. 1990.

21. Beattie, G. J., "Design of slender precast concrete wall panels - experimental testing", Building Research Association of New Zealand (BRANZ), Draft Study Report, 2003.

22. Chiewanichakorn, M., "Stability of thin precast concrete wall panels subjected to gravity and seismic forces", ME Thesis, Dept. of Civil Engineering, University of Canterbury, Nov. 1999.

23. Whiteside, M., "The performance of slender precast conventionally reinforced cantilever walls incorporating steel fibre reinforced concrete under seismic forces", ME Thesis, Dept. of Civil Engineering, University of Canterbury, Feb. 2000.

24. McMenamin, A., "The performance of slender precast reinforced concrete cantilever walls with roof level lateral displacement restraint under simulated in-plane seismic loading", ME Thesis, Dept. of Civil Engineering, University of Canterbury, Mar. 1999.

25. Synge, A. J., "Ductility of squat shear walls", Dept. of Civil Engineering, University of Canterbury, Report No. 80-8, Feb. 1980.

26. Spurr, D. D., "Post-elastic behaviour of reinforced concrete frame wall components and assemblages subjected to simulated seismic loading", PhD Thesis, Dept. of Civil Engineering, University of Canterbury, 1984.

27. Santhkumar, A. R., "Ductility of coupled shear walls", PhD Thesis, Dept. of Civil Engineering, University of Canterbury, 1974.

28. Goodsir, W. J., "The design of coupled frame-wall structures for seismic actions", PhD Thesis, Dept. of Civil Engineering, University of Canterbury, 1985.

29. Paulay, T., "Seismic displacement capacity of ductile reinforced concrete building systems", Bulletin of NZ Society for Earthquake Engineering, No. 1, Vol. 36, Mar. 2006, pp. 47-65.

30. Fenwick, R. C., "Strength degradation of concrete beams under cyclic loading", Bulletin of NZ Society for Earthquake Engineering, Vol. 16, No. 1, Mar. 1983, pp. 25-38. 
Table 1: Limiting material strains for potential plastic regions [NZS3101:2006 ${ }^{3}$ ]

\begin{tabular}{|l|lll|}
\hline $\begin{array}{l}\text { Potential plastic region } \\
\text { classification }\end{array}$ & $\begin{array}{l}\text { Material strain limits } \\
\text { Section curvature ductility in flexural plastic hinge region) }\end{array}$ \\
\hline Nominally ductile (NDPR) & Unidirectional $\quad 5\left(\alpha_{\mathrm{fy}}\right)$ & Reversing $\quad 3\left(\alpha_{\mathrm{fy}}\right)$ \\
\hline Limited ductile (LDPR) & Unidirectional $30\left(\alpha_{\mathrm{fy}}\right)$ & Reversing & $15\left(\alpha_{\mathrm{fy}}\right)$ \\
\hline Ductile (DPR) & Unidirectional $60\left(\alpha_{\mathrm{fy}}\right)$ & Reversing & $30\left(\alpha_{\mathrm{fy}}\right)$ \\
\hline$\alpha_{f y}=\frac{400}{f_{y}} \quad$ but not exceeding $1.1\left(f_{y}\right.$ in MPa) & & \\
\end{tabular}

2

3

4

5

6

7

8

9

10

11

12

13

14

15

Table 2: Summary of ultimate curvatures from test results

\begin{tabular}{|c|c|c|c|c|c|}
\hline & \multirow{2}{*}{$\begin{array}{l}\text { Beams } \\
\text { Ductile }\end{array}$} & \multicolumn{2}{|c|}{ Columns } & \multicolumn{2}{|c|}{ Walls } \\
\hline & & $\begin{array}{l}\text { Limited } \\
\text { ductile }\end{array}$ & Ductile & $\begin{array}{l}\text { Single } \\
\text { layer } \\
\text { reinforcing }\end{array}$ & $\begin{array}{l}\text { Ductile double } \\
\text { layer } \\
\text { Reinforcing }\end{array}$ \\
\hline Average & $27.3 K_{y}$ & $18.5 K_{y}$ & $26.8 K_{y}$ & $9.3 K_{y}$ & $20.6 K_{y}$ \\
\hline Std. deviation & $5.8 K_{y}$ & $4.9 K_{y}$ & $5.9 K_{y}$ & $2.4 K_{y}$ & $4.1 K_{y}$ \\
\hline Lower Characteristic & $17.7 K_{v}$ & $10.4 K_{v}$ & $17.0 K_{v}$ & $5.4 K_{v}$ & $13.9 K_{v}$ \\
\hline Number of units & 19 & 7 & 9 & 20 & 7 \\
\hline
\end{tabular}

The correction factor for grade of reinforcement, $K_{y}$ is given in Equation 8.

Table 3: Recommended $K_{d}$ values for reversing plastic regions

\begin{tabular}{|c|c|c|c|c|c|c|c|}
\hline \multicolumn{3}{|c|}{ Beams } & \multicolumn{2}{|c|}{ Columns } & \multicolumn{3}{|c|}{ Walls } \\
\hline $\begin{array}{l}\text { Nominally } \\
\text { Ductile }^{\circledR}\end{array}$ & $\begin{array}{l}\text { Limited } \\
\text { Ductile }\end{array}$ & Ductile & $\begin{array}{l}\text { Nominally } \\
\& \text { limited } \\
\text { Ductile }\end{array}$ & Ductile & $\begin{array}{l}\text { Nominally } \\
\text { ductile }^{\circledR}\end{array}$ & $\begin{array}{l}\text { Limited } \\
\text { ductile }^{*}\end{array}$ & Ductile** \\
\hline $\begin{array}{l}\varepsilon_{c} \leq 0.0025 \\
\varepsilon_{s} \leq 0.010\end{array}$ & 10 & 17.5 & 10 & 17.5 & $\begin{array}{l}\varepsilon_{c} \geq 0.0025 \\
\varepsilon_{s} \geq 0.010\end{array}$ & $\begin{array}{l}5.0 \\
8.5^{+} \\
\end{array}$ & $\begin{array}{l}12.5 \\
15.0^{+} \\
\end{array}$ \\
\hline
\end{tabular}

* limited ductile doubly reinforced and singly reinforced walls

** two layers of reinforcement in each direction and confined as required by the $\mathrm{Code}^{3}$

$+\quad$ for walls with confined boundary elements which resist $70 \%$ or more of compression force calculated as for the ultimate limit state

(a) for nominally ductile beams \& walls, permissible strains in concrete and reinforcement $\left(\varepsilon_{\mathrm{c}}\right.$ and $\left.\varepsilon_{\mathrm{s}}\right)$ are specified, not $k_{d}$ values 

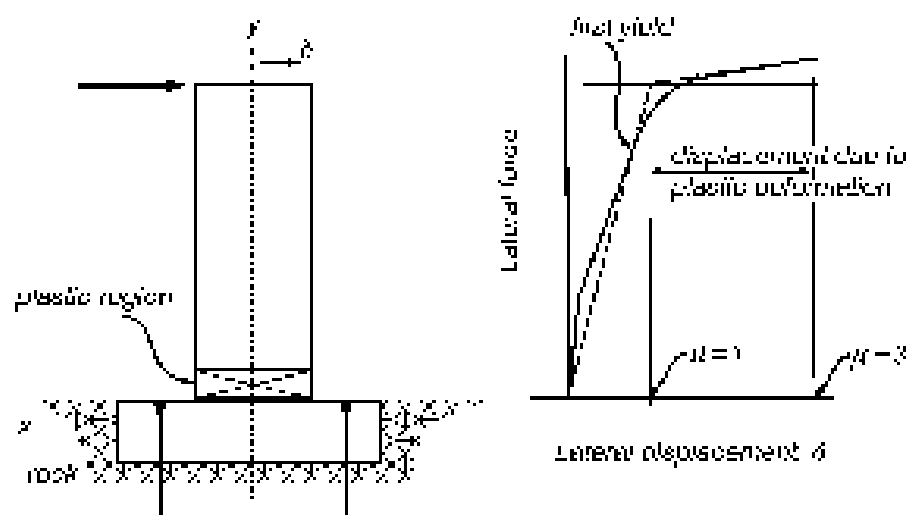

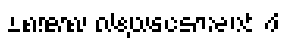

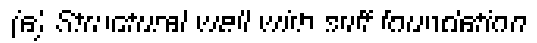
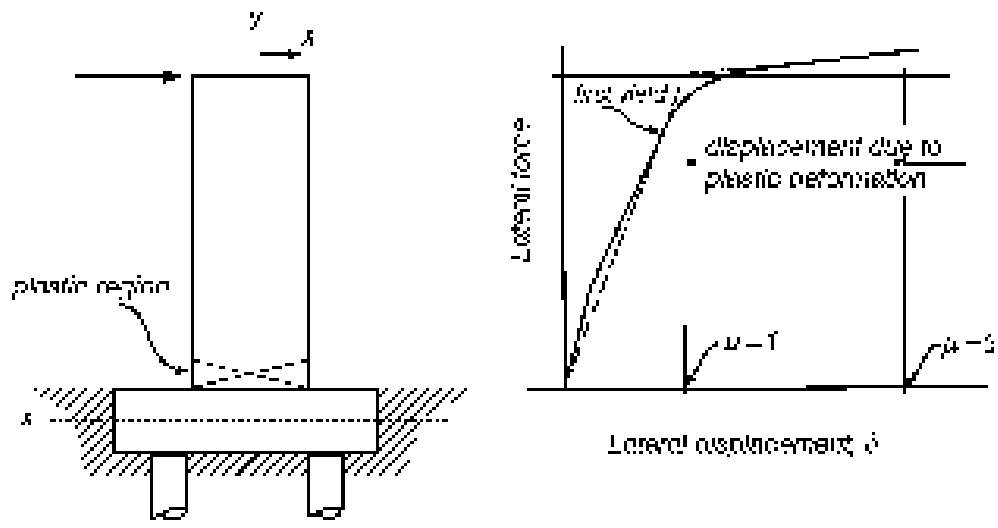

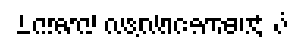

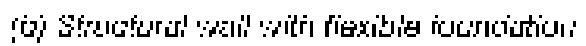

Figure 1. Effect of foundation rigidity on displacement ductility 


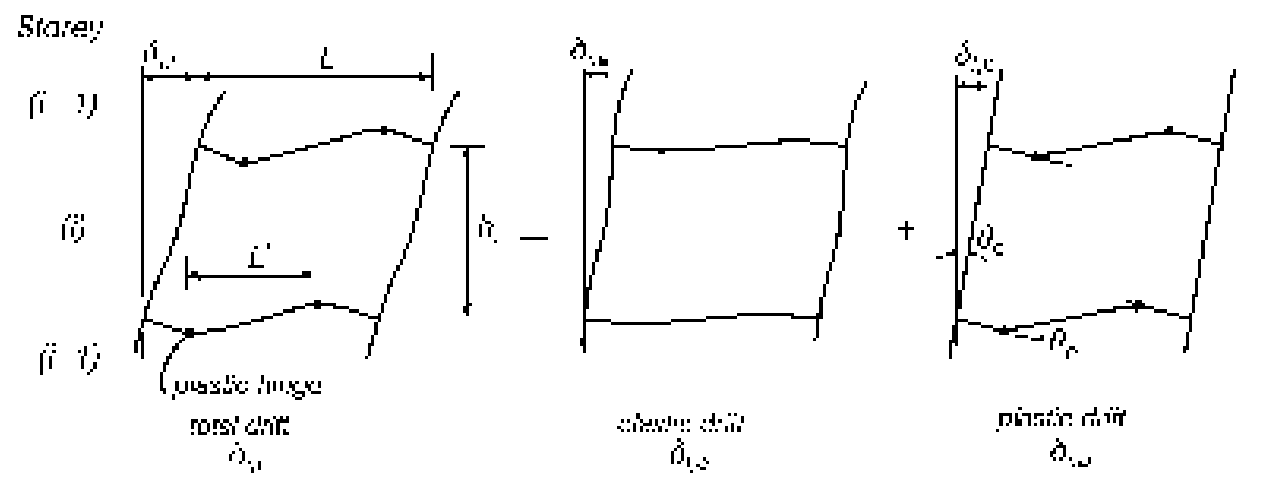

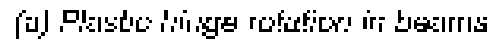

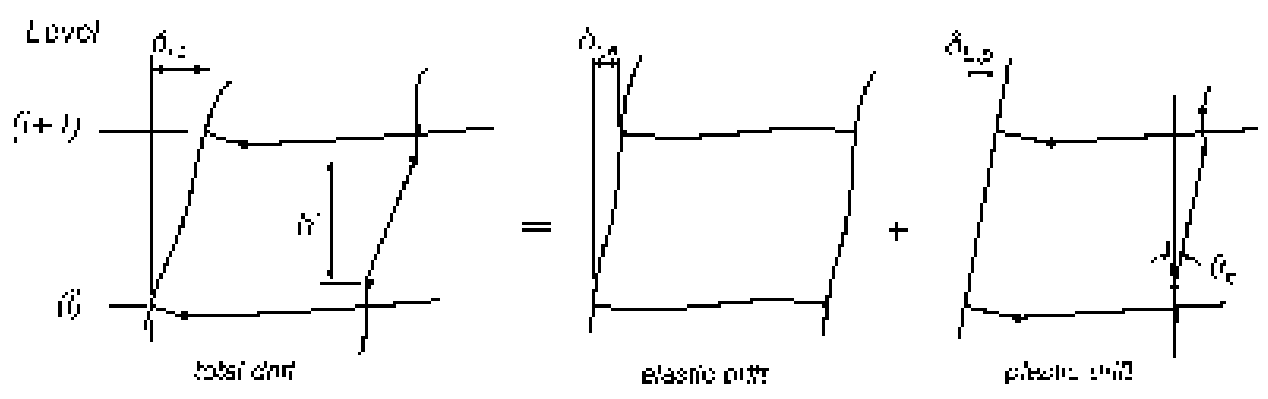

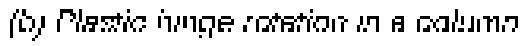

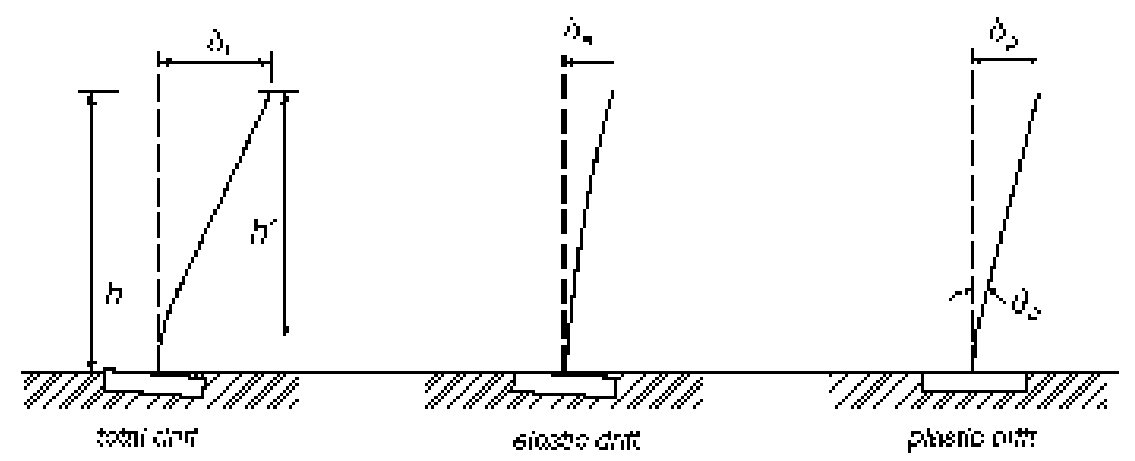

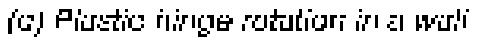

Figure 2. Calculation of plastic hinge rotations 


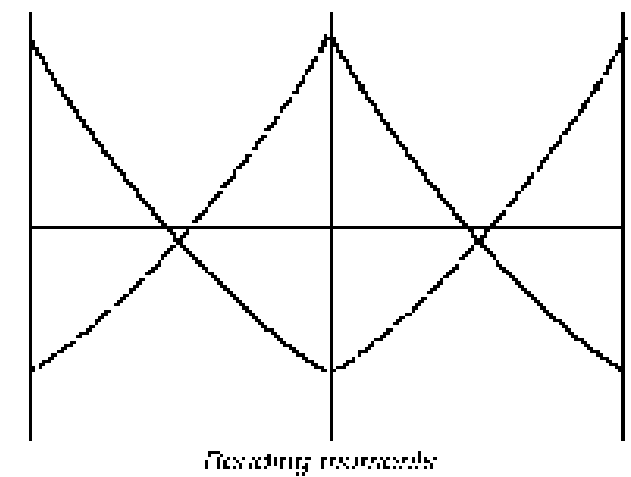

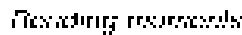

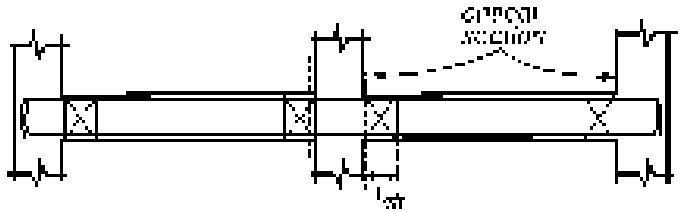

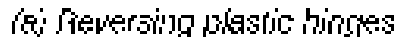
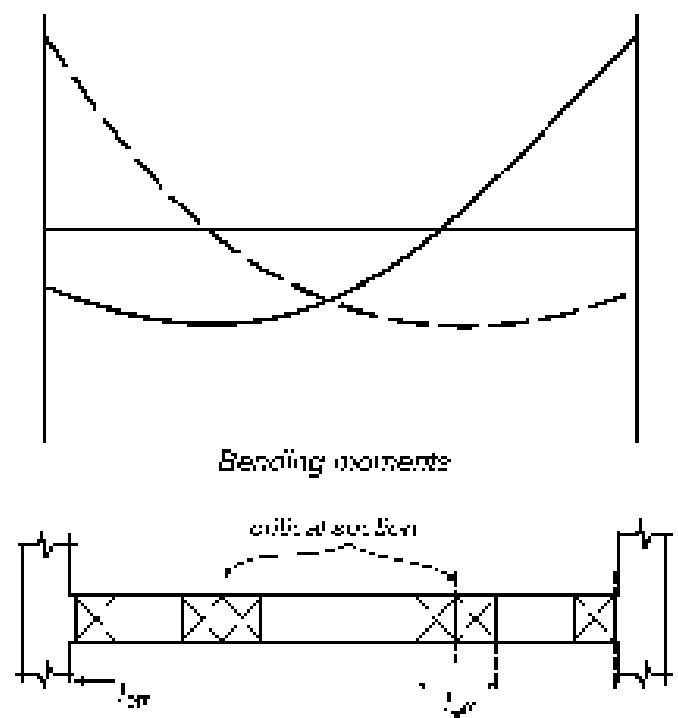

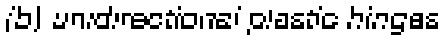

Figure 3. Effective plastic hinge lengths for reversing and unidirectional plastic hinges 


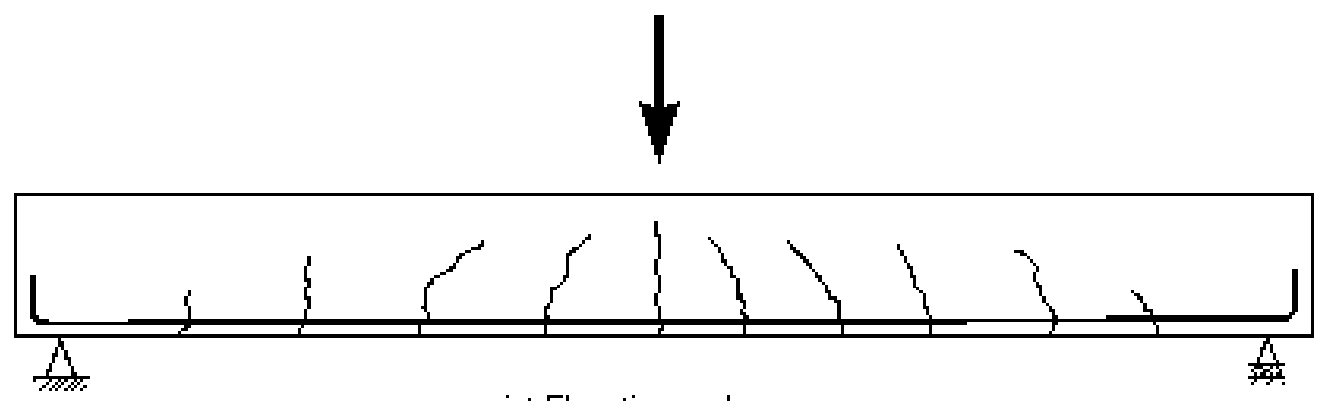

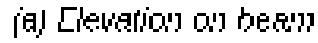

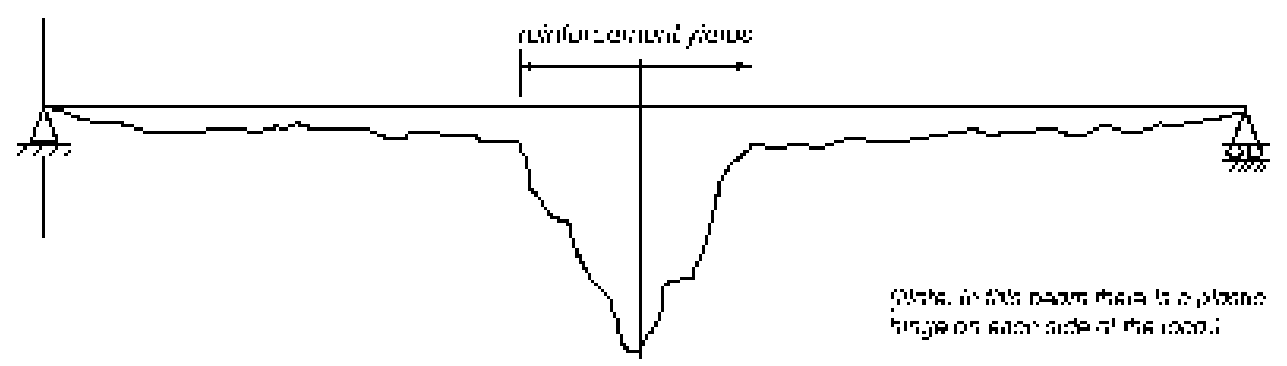

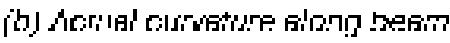

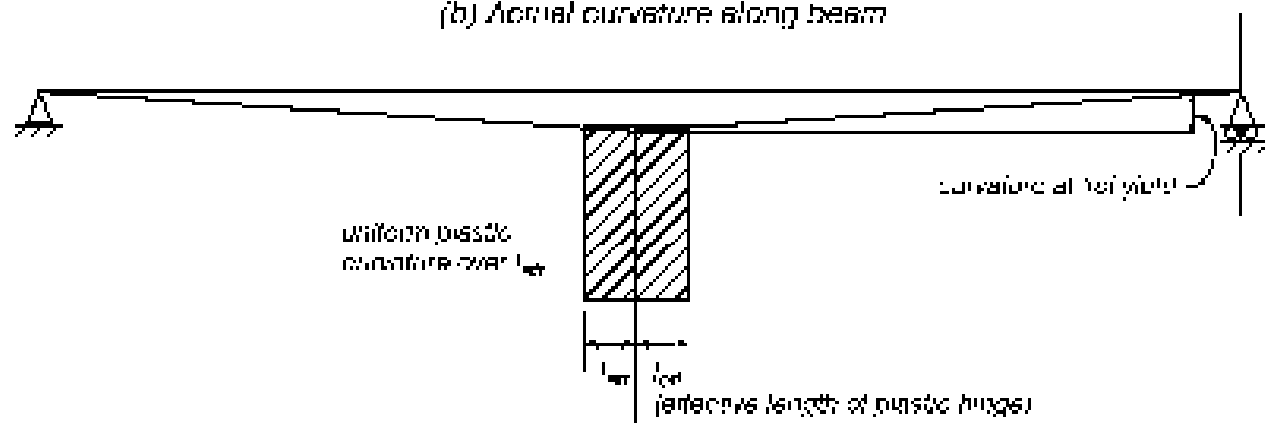

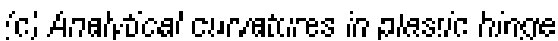

Figure 4. Actual and analytical curvatures in a beam sustaining plastic deformations 


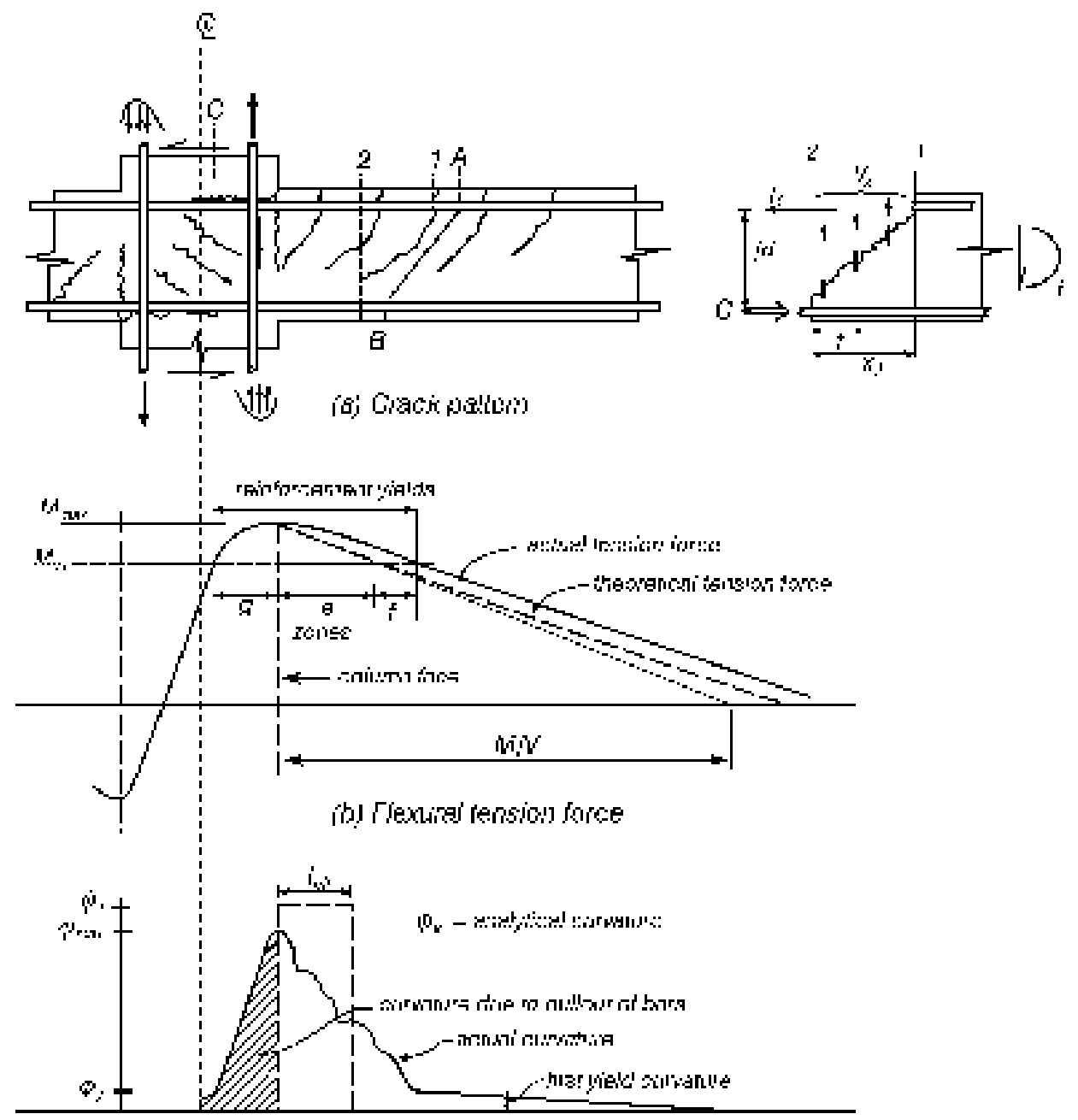

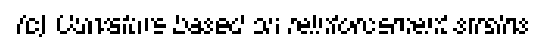

Figure 5. Deformations in a plastic region in a beam 


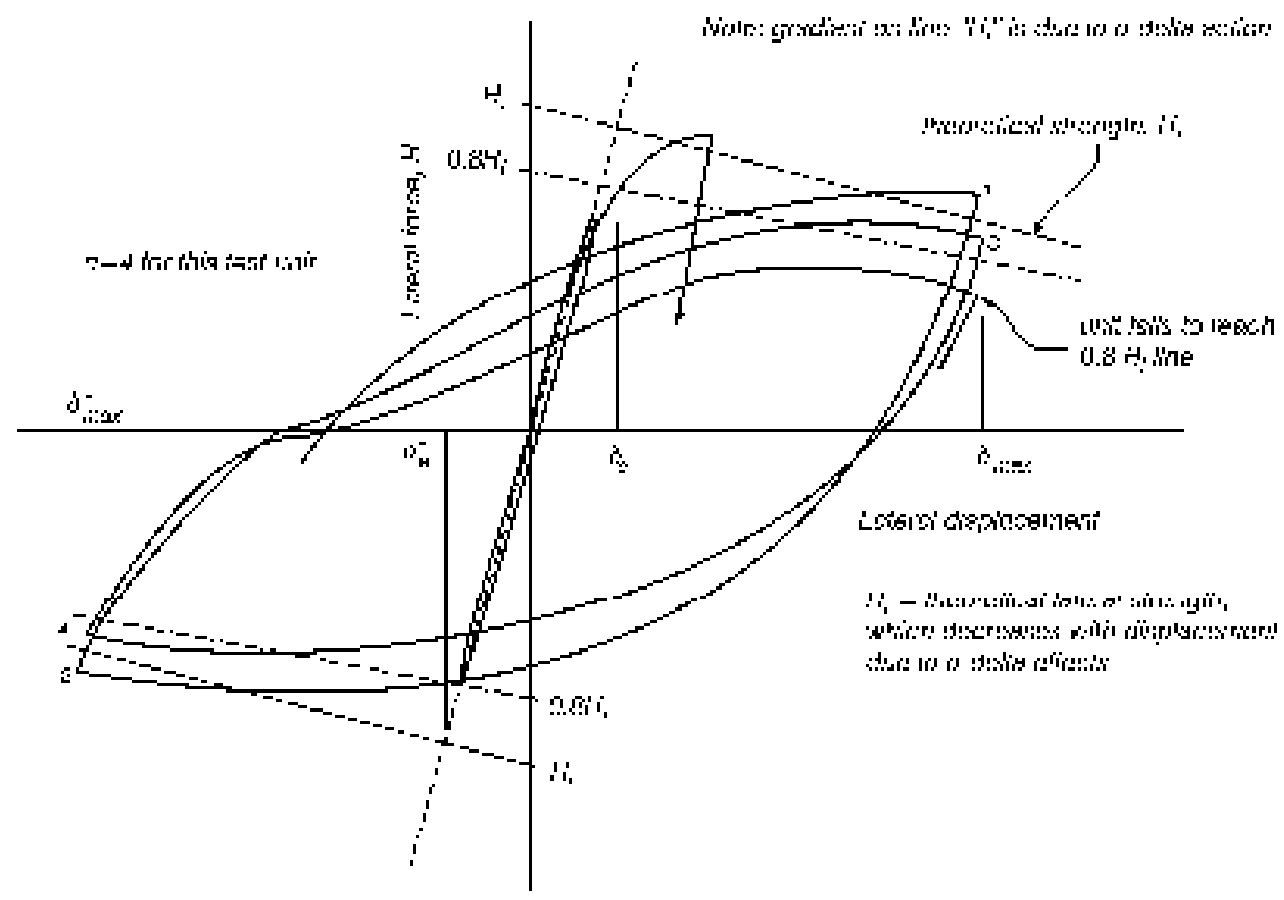




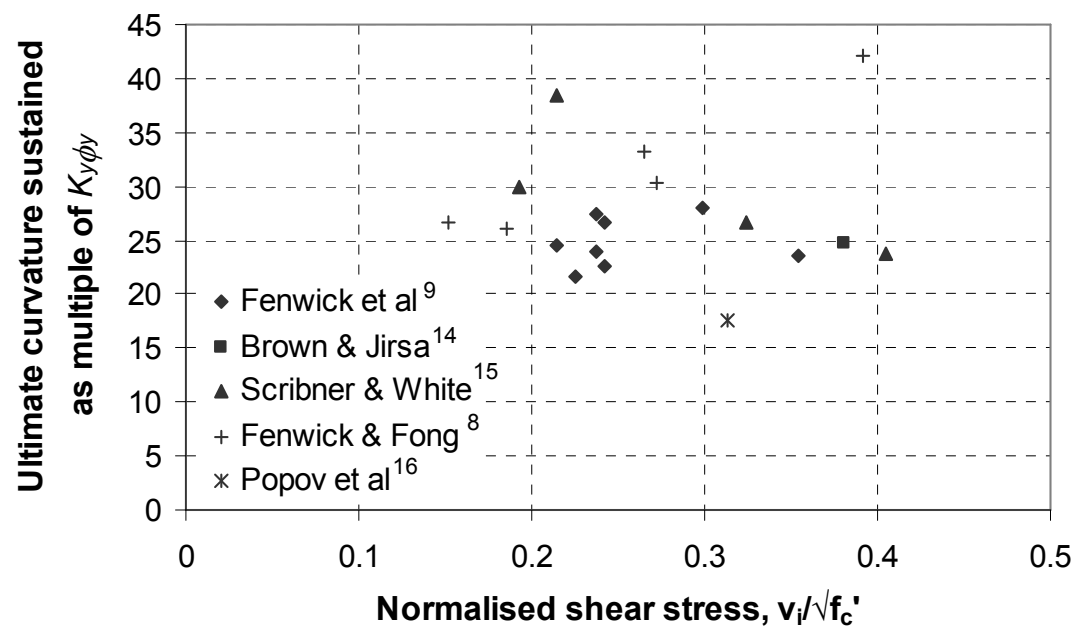

Figure 7. Ultimate curvatures sustained in beam tests 


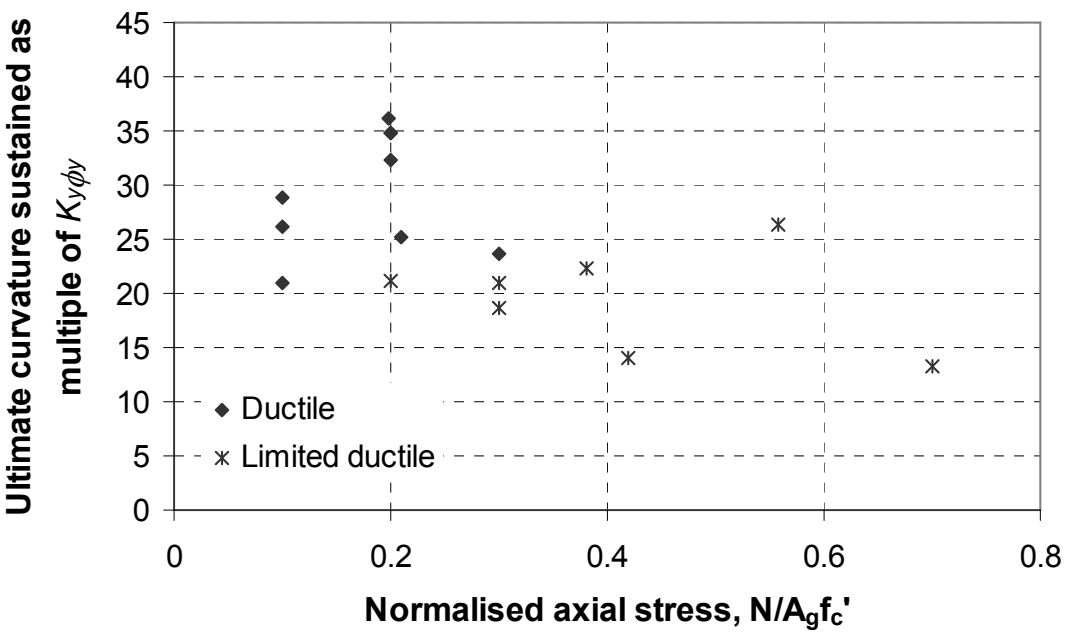

Figure 8. Ultimate curvatures sustained in column tests

3

4 


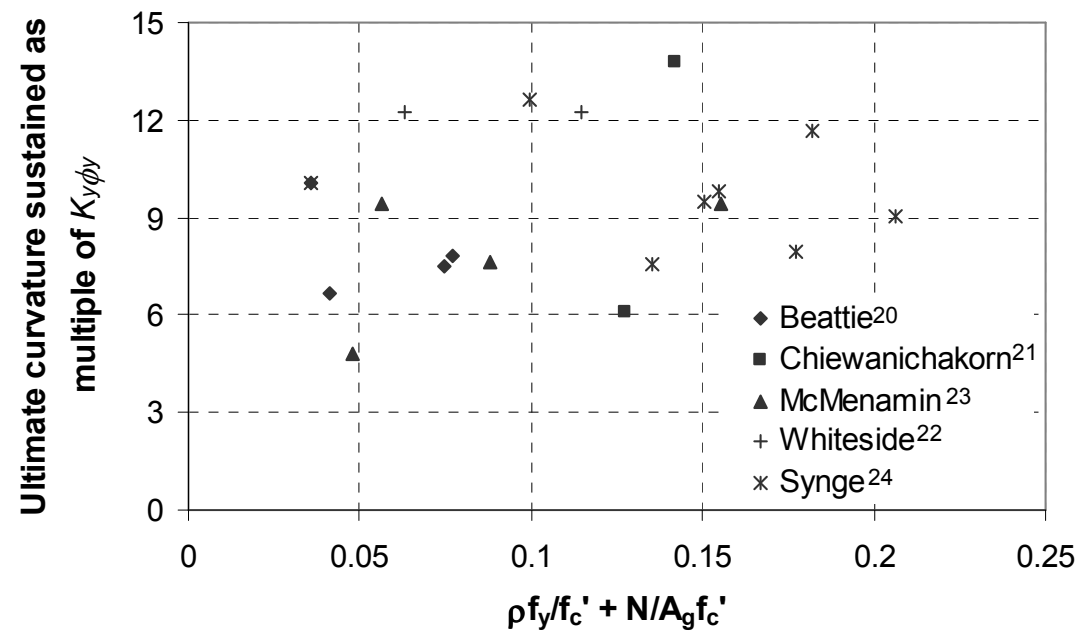

2

3

4

5

6

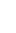

Figure 9. Ultimate curvatures sustained in singly reinforced walls 